\title{
THE CHANGING ROLE OF BANKS AND THE CHANGING VALUE OF DEPOSIT GUARANTEES
}

by Peter Ritchken, James Thomson, and Ivilina Popova

Peter Ritchken is a professor of banking and finance at the Weatherhead School of Management, Case Western Reserve University; James Thomson is an assistant vice president and economist at the Federal Reserve Bank of Cleveland; and Ivilina Popova is a Ph.D. candidate in the Department of Operations Research, Case Western Reserve University.

Working papers of the Federal Reserve Bank of Cleveland are preliminary materials circulated to stimulate discussion and critical comment. The views stated herein are those of the authors and not necessarily those of the Federal Reserve Bank of Cleveland or of the Board of Governors of the Federal Reserve System.

May 1995 


\begin{abstract}
This article develops a model for pricing deposit guarantees. The model treats the bank's investments as a portfolio of default-free bonds and risky loans. The risk of the loans is determined by individual firms' financing and investment decisions. Pushing back risk to the level of the borrowing firms allows us to link deposit guarantees to specific characteristics of these loans, such as their durations, and to correlations between business risk and interest rates. Since the nature of bank loans has been changing over time, our model should predict the accompanying change in value of the government guarantees.
\end{abstract}




\section{Introduction}

Traditional models of deposit insurance assume that a bank's assets follow an exogenously provided stochastic process. If the process is Geometric Wiener, then, as Merton [1977] has shown, an isomorphic correspondence exists between loan guarantees and common-stock put options, and a simple formula exists for deposit insurance. Merton's analysis has since been extended in a number of ways. Merton [1978], for example, evaluates the cost of deposit insurance taking into account surveillance costs and random auditing times. Buser, Chen, and Kane [1981] and Marcus [1984] introduce charter values into the analysis. McCulloch [1981a] and Crouhy and Galai [1991] consider the implications of interest rate risk, and Ritchken et al. [1993] consider the case where the bank adapts its portfolio and capital structure decisions dynamically in order to exploit the insurance subsidy more fully. ${ }^{1}$

The objective of this study is to develop models of deposit guarantees that capture more realism than existing models, thereby permitting a wider range of analyses to be performed. We extend the literature by modeling bank assets as risky debt issued by firms. ${ }^{2}$ The value of this debt is equivalent to a portfolio consisting of a long position in default-free bonds and a short position in put options on the assets of the bank's loan customers. The value of the put options, in turn, depends on the investment and financing decisions of the bank's loan customers. Pushing bank asset risk back to the level of the borrowing firms allows us to explore several new areas more thoroughly than have previous models. For example, the current literature has not explicitly focused on how the types of loans made by banks affect the value of deposit guarantees. There is a strand of literature that shows how regulatory policies increase the correlation of default risk across bank portfolios (Penati and Protopapadakis [1988]) as well as across assets in a given bank's portfolio (Flannery [1989]). However, little attention has been focused on how the characteristics of bank loan customers affect the value of deposit guarantees. What we do know is that these characteristics continue to change over time. Boyd and Gertler [1994], for example, report that the nature of risky loans made by banks has changed significantly over the last decade, and these changes may have important consequences for deposit insurance. By pushing back asset risk to the level of the

\footnotetext{
${ }^{1}$ The literature on deposit insurance is vast. For a review, see Flood [1990] and Merton and Bodie [1992].

${ }^{2}$ When bank assets are modeled as risky debt, the upside gains are limited to the principal and interest on the loans. Ignoring this cap on asset-value appreciation may overstate the potential gains from moral hazard and hence may lead to high-biased estimates of the value of deposit guarantees.
} 
borrowing firms, we are able to explore specific firm effects on deposit guarantees. In particular, the value of risky loans, and hence of deposit guarantees, is influenced by the capital structure of the borrowing firms, by correlation effects between the assets of the firm and interest rates, by loan duration, and by other borrower-related factors.

Discerning these linkages is crucial for understanding how regulatory policies can affect credit availability for different types of firms.

The paper proceeds as follows. In section II, we provide some evidence that the nature of loans issued by banks has changed over time. This motivates the need for models of deposit insurance that explicitly capture properties of the risky loans held by banks. Section III develops the basic model for an insured bank that invests in risky loans and government bonds. Uncertainty is represented by credit and interest rate risk. In section IV, an explicit model of deposit insurance is provided when no interest rate risk is present. Deposit guarantees can be viewed as a put option contract on a portfolio of risky debt and government bonds. Since risky debt itself is modeled as straight debt less a default premium (captured by a put option), the deposit guarantee is a compound option. Section IV analyzes this option and identifies how the quality of loans made by the bank affects the value of the deposit guarantee. Section V generalizes the model when interest rate risk is present. With two sources of uncertainty, the value of the deposit guarantee depends on the correlation between credit and interest rate risks and other factors. Section VI summarizes the paper.

\section{The Changing Role of Banks}

There is an ongoing debate as to the viability of banks as an industry. Gorton and Rosen [1992] find that banking is a declining industry fraught with overcapacity. Boyd and Gertler [1994] question the use of traditional measures of intermediation in assessing the viability of the banking industry. They find that when one accounts for changes in the types of services banks provide, the industry seems to be thriving in the new, more competitive financial marketplace.

While the future of banks as intermediaries is far from certain, what is clear is that the composition of bank portfolios and bank customers is changing. This is illustrated in figure 1 , which shows trends in loan composition since 1988. The percentage of the loan portfolio invested in commercial and industrial (C\&I) loans, once the mainstay of banking, has declined over time, while the portfolio shares of other types of loans 
(particularly commercial real estate, consumer, and home mortgage loans) have risen. Furthermore, the composition of bank C\&I loan customers has shifted over time from major corporations to smaller buśinesses.

Another indication of the change in bank intermediation is the changing maturity structure of bank assets. Figure 2 shows that the average effective maturity of bank loans and total earning assets has steadily increased since 1988. While some of this increased maturity intermediation is a consequence of the asymmetric treatment of credit and interest rate risks under the Bank for International Settlements' risk-based capital guidelines (see Li et al. [1995]), the trend signals a fundamental change in the types of loans banks are making. These changes in the composition and maturity structure of bank loan portfolios have implications for banking regulation and federal deposit insurance. ${ }^{3}$ In the following sections, we develop a simple model of an insured bank that contains elements which reflect the changing nature of the outstanding loans.

\section{A Model of an Insured Bank}

We assume that the market for default-free bonds is competitive. Banks invest in risky loans and government bonds. We further assume that the owners of the bank are also its managers. At date 0 , they fund the asset portfolio with $\alpha$ dollars of equity and $D(0)=1-\alpha$ dollars of deposits fully insured by a government agency. This agency charges the bank a flat-rate premium per dollar of deposit. The value of deposit insurance at date 0 , denoted by $G(0)$, can be viewed as government-contributed capital. The insurance provides depositors with full protection over the period $[0, \tau]$, at which time they renew their deposits if the bank is solvent. The insurer is assumed to strictly enforce the closure policy at date $\tau$. Specifically, if the market value of the bank's tangible assets is below the deposit base at this date, the bank is immediately closed.

At date 0 , the bank lends $q$ dollars to a representative firm. The firm has $e_{f}$ dollars in cash and invests $A(0)=\left(q+e_{f}\right)$ dollars into a risky project. The firm owes the bank $q^{*}$ dollars, due at date $\mathrm{T}$. Let $B(\mathrm{t}, \mathrm{T})$ be the value of the risky loan at date $\mathrm{t}$. Clearly, at date $0, q^{*}$ is determined so that $B(0, T)=q$.

\footnotetext{
${ }^{3}$ McCulloch [1981b] contends that maturity intermediation is a consequence of deposit insurance and not a natural form of intermediation for depository institutions.
} 
The balance sheet of the representative borrowing firm is shown below.

\section{Balance Sheet of Representative Firm}

\begin{tabular}{|ll|}
\hline Risky investment: $A(0)$ & Loan from bank: $B(0)=\mathrm{q}$ \\
& Firm shareholder equity: $e_{f}$ \\
& \\
\hline Total: $A(0)$ & Total: $e_{f}+\mathrm{q}$ \\
\hline
\end{tabular}

In addition to providing loans to firms, the bank invests $I(0)=1-q$ dollars in government discount bonds with maturity date $s$. Let $P(\mathrm{t}, \mathrm{s})$ be the date $\mathrm{t}$ price of a default-free pure discount bond that pays $\$ 1$ at date $s$. Since $P(0, s)$ is the price of a pure discount bond at date 0 , the number of bonds purchased is $(1-q) / P(0, s)$.

The bank raises $D(0)=1-\alpha$ dollars in deposits, with shareholders providing $\alpha$ dollars. The bank's deposits are guaranteed by the government. The value of the subsidy arising from these guarantees is $G(0)$. The balance sheet of the bank at date 0 is shown below.

\section{Balance Sheet of Bank}

Risky loan: $B(0, T)=q$

Deposits: $D(0)=1-\alpha$

Default-free loan: $I(0)=1-q$

Shareholder equity: $e(0)$

Government subsidy: $G(0)$

Total: $\quad 1+G(0) \quad$ Total: $\quad(1-\alpha)+e(0)$

Shareholder equity at date 0 , represented by $e(0)$, is therefore given by

$$
e(0)=\alpha+G(0)
$$


There are two sources of uncertainty, namely, the risky investment adopted by the representative firm and the evolution of the yield curve. The dynamics of the risky investment are given by

$$
\frac{d A(t)}{A(t)}=\mu_{A}(A, t) d t+\sigma_{A} d z(t)
$$

with $A(0)=e_{f}+q$. Here, $\mu_{A}(A, t)$ is the drift term, $\sigma_{A}$ is the instantaneous volatility, and $d z(t)$ is the standard Wiener increment.

Bond prices are linked to forward rates by

$$
P(t, s)=e^{-\int_{t}^{s} f(t, x) d x}
$$

Here, $f(t, x)$ is the instantaneous forward rate at time $t$ for the time increment $[\mathrm{x}, \mathrm{x}+\mathrm{dx}]$. Forward rates are assumed to follow a diffusion process of the form

$$
d f(t, s)=\mu_{f}(t, s) d t+\sigma_{f}(t, s) d w(t) \quad \forall s>t
$$

with the forward rate function, $f(0, \bullet)$, initialized to the observed value. Here, $\mu_{f}(t, s)$, $\sigma_{f}(t, s)$, and $d w(t)$ are the drift, the volatility structure, and the Wiener increment, respectively. We assume that all forward rates are correlated with the asset returns. In particular, $E\{d w(t), d z(t)\}=\rho d t$. We follow Heath, Jarrow, and Morton (hereafter HJM) [1992] and assume that $\sigma_{f}(t, \cdot)$ is an exponentially dampened function of the form

$$
\sigma_{f}(t, s)=\sigma e^{-\kappa(s-t)}
$$

where $\sigma, k 0$. Under this model, HJM show that the price of a bond at date $t$ is related to its price at date 0 through

$$
P(t, T)=\frac{P(0, T)}{P(0, t)} e^{-\frac{1}{2} \beta^{2}(t, T) \phi(t)+\beta(t, T)[f(0, t)-r(t)]}
$$


where

$$
\begin{aligned}
& \phi(t)=\frac{\sigma^{2}}{2 \kappa}\left[1-e^{-2 \kappa t}\right] \\
& \beta(t, T)=\frac{1}{\kappa}\left[1-e^{-2 \kappa(T-t)}\right] .
\end{aligned}
$$

They also show that the dynamics of the state variable, $r(t)$, are given by

$$
d r(t)=\mu_{r}(t) d t+\sigma d w(t)
$$

where, for pricing purposes, the drift can be taken $\mathrm{as}^{4}$

$$
\mu_{r}(t)=\kappa[f(0, t)-r(t)]+\frac{\sigma^{2}}{2 \kappa}\left[1-e^{-2 \kappa t}\right]+\frac{d f(0, t)}{d t}
$$

Now consider the value of the risky loan at date t, $0 \leq \mathrm{t} \leq \mathrm{T}$. Following Merton [1977], a risky loan with face value $q^{*}$ is equivalent to default-free debt together with a short position in a put option on the firm's assets with exercise price $q^{*}$ and expiration date T. At expiration, if the firm cannot pay $q^{*}$, it surrenders its assets to the bank. Hence,

$$
B(t, T)=q^{*} P(t, T)-p^{E}\left(t, T ; q^{*}\right)
$$

where $p^{E}\left(t, T ; q^{*}\right)$ is the value of the put option. For the volatility structure given in equation (6), Ritchken and Sankarasubramanian [1991] show that

$$
p^{E}\left(t, T ; q^{*}\right)=q^{*} N\left(-d_{2}\right)-A(t) N\left(-d_{1}\right)
$$

where

$$
\begin{aligned}
& d_{1}=\left[\ln \frac{A(t)}{q^{*} P(t, T)}+\frac{1}{2} \sigma_{y}^{2}\right] / \sigma_{y} \\
& d_{2}=d_{1}-\sigma_{y}
\end{aligned}
$$

and

\footnotetext{
${ }^{4}$ In particular, any European interest rate claim with a cash payment at date $s$ can be priced as $C(0)=E_{0}\left[\exp \left(\int_{0}^{S} r(x) d x\right) C(T)\right]$, where the expectation is taken under the process in equation (7).
} 


$$
\sigma_{y}^{2}=\sigma_{A}^{2}(T-t)+\frac{\sigma_{A}^{2}}{2 \kappa^{3}}\left[2 \kappa(T-t)-3+4 e^{-\kappa(T-t)}-e^{-2 \kappa(T-t)}\right]-\frac{2 \rho \sigma_{A} \sigma}{\kappa^{2}}\left[\kappa(T-t)-1+e^{-\kappa(T-t)}\right] .
$$

If interest rates are certain and the term structure is flat, then the above price of the risky loan in equation (8) simplifies, with the put price computed using equation ( $9 \mathrm{~b})$ below.

$$
p^{E}\left(t, T ; q^{*}\right)=q^{*} N\left(-d_{2}\right)-A(t) N\left(-d_{1}\right)
$$

where

$$
\begin{aligned}
& d_{1}=\left\{\left[\ln \left(A(t) / q^{*}\right]\left(r+\sigma_{A}^{2} / 2\right)(T-t)\right\} / \sigma_{A} \sqrt{T-t}\right. \\
& d_{2}=d_{1}-\sigma_{A} \sqrt{T-t}
\end{aligned}
$$

The value of the default-free position at date $t, I(t)$, is given by

$$
I(t)=\left[\frac{1-q}{P(0, s)}\right] P(t, s)
$$

For certain interest rates, the above equation reduces to

$$
I(t)=(1-q) e^{r t}
$$

Let V(t) be the value of the firm's "tangible" assets at date $t$. Specifically,

$$
V(t)=I(t)+B(t, T)
$$

The duration of the deposit base is assumed to be $\tau$. At that date, the level of deposits is given by

$$
D(\tau)=D(0) / P(0, \tau)
$$

If interest rates are certain and constant, then equation (12a) reduces to

$$
D(\tau)=(1-\alpha) e^{r \tau}
$$


At audit date $\tau$, the bank passes the audit test if the value of these tangible assets exceeds the deposits.

\section{Pricing Deposit Guarantees under Interest Rate Certainty}

Consider a bank with capital $\alpha$, deposits $1-\alpha$, and investment consisting of q dollars in risky loans of maturity $\mathrm{T}$ plus $1-\mathrm{q}$ dollars in default-free bonds. The $\mathrm{q}$ dollars are combined with $e_{f}$ dollars of firm-supplied capital and are invested in a risky project.

Since there is no interest rate uncertainty, the risk premium for the risky debt can be computed using equations ( 8 ) and (9b). In particular, the face value of the debt, $\mathrm{q}^{*}$, is given by the solution to

$$
B(0, T)=q=q^{*} e^{-r T}-p^{E}\left(0, T ; q^{*}\right)
$$

where $p^{E}\left(0, T ; q^{*}\right)$ is given in equation (9b). The value of the government subsidy at date $\tau, G(\tau)$, is given by

$$
G(\tau)=\operatorname{Max}[0, D(\tau)-V(\tau)]
$$

Substituting for $D(\tau)$ and $V(\tau)$, from equations (10b), (11), and (12b) we obtain

$$
G(\tau)=\operatorname{Max}\left[0, K\left(\alpha, q ; q^{*}\right)+p^{E}\left(\tau, T ; q^{*}\right)\right]
$$

where $K\left(\alpha, q ; q^{*}\right)$ is a constant given by

$$
K\left(\alpha, q ; q^{*}\right)=(q-\alpha) e^{r \tau}-q^{*} e^{-r(T-\tau)}
$$

Equation (15) shows that the government subsidy is a rather complex compound option. The fair price of the deposit guarantee at date $0, \mathrm{G}(0)$, is given by

$$
G(0)=E_{0}\{G(\tau)\} e^{-r \tau}
$$

where the expectation is taken under the risk-neutralized process given by equation (2), with the drift term taken as $\mu_{A}(A, t)=r A(t)$. 
The following proposition establishes the fair value of the deposit guarantee.

\section{Proposition}

Consider a bank with capital $\alpha$, deposits $1-\alpha$, and investment consisting of $q$ dollars in risky loans of maturity $T$ and 1 -q dollars in default-free bonds. The deposits earn the riskless rate rover the period to the audit date, $\tau$, with $\tau \leq T$. The value of the q dollars is combined with $e_{f}$ dollars of firm-supplied capital and is invested in a risky project, with volatility $\sigma_{A}$. The value of the government guarantee at date 0 is given by $G(0)$, where

$$
\begin{aligned}
G(0)= & \left(q-\alpha-q^{*} e^{-r T}\right) N\left(z^{*}\right)+q^{*} e^{-r T} N_{2}\left[z^{*},-\sqrt{\frac{T-\tau}{T}} d ; \sqrt{\frac{\tau}{T}}\right] \\
& -A(0) N_{2}\left[z^{*}-\sigma_{A} \sqrt{\tau},-\sigma_{A} \sqrt{T-\tau}-d-\frac{\sigma \tau}{\sqrt{T-\tau}} ; \sqrt{\frac{\tau}{T}}\right],
\end{aligned}
$$

where

$$
d=\left(\frac{\ln A(0) / q^{*}+\left(r-\sigma_{A}^{2} / 2\right) T}{\sigma_{A} \sqrt{T-\tau}}\right)
$$

and $N_{2}(x, y ; \rho)$ is the cumulative standard bivariate normal distribution, evaluated at $(x, y)$ when the correlation coefficient is $\rho$.

Proof: See appendix.

Figure 3 shows the sensitivity of the government guarantee to the maturity of the risky debt. Notice that as the duration of the loan increases, so too does the risk and the value of the government subsidy. For large maturity values over the time to the audit date, the dynamics of the bond are somewhat similar to the dynamics of an asset. However, for shorter maturity loans, the dynamics of the bond become more predictable as its value is drawn toward its face value. Figure 3 also shows the sensitivity of the government subsidy to the leverage ratio of the representative borrowing firm. As this ratio expands, the risk of default increases, as does the value of the government subsidy. In an interestrate-certainty environment, the bank will exploit the government guarantee by providing 
the most risky loans. This is accomplished by providing long-term funds to the most highly leveraged firms.

For the degenerate case, when $\mathrm{T}=\tau$, equation (17) reduces to

$$
G(\tau)=\operatorname{Max}\left[0,(q-\alpha) e^{r \tau}-A(\tau)\right]
$$

and hence

$$
G(0)=(q-\alpha) N\left(-d_{2}\right)-A(0) N\left(-d_{1}\right)
$$

where

$$
\begin{aligned}
& d_{1}=\left[\ln [A(0) /(q-\alpha)]+\sigma_{A}^{2} \tau / 2\right] / \sigma_{A} \sqrt{\tau} \\
& d_{2}=d_{1}-\sigma_{A} \sqrt{\tau}
\end{aligned}
$$

Moreover, in this case the payout to the bank's shareholders at date $\tau$ is given by

$$
e(\tau)=\operatorname{Max}[0, V(\tau)-D(\tau)]
$$

Substituting equations (13b), (11b), and (12) into the above expression, we obtain

$$
e(\tau)= \begin{cases}(\alpha-q) e^{r \tau}+q^{*} & \text { if } A(\tau) \geq q^{*} \\ \operatorname{Max}\left[0,(\alpha-q) e^{r \tau}+A(\tau)\right] & \text { otherwise }\end{cases}
$$

Figure 4 shows the payouts to the bank at date $\tau$. Note that the bank's maximum upside potential is limited to $(\alpha-q) e^{r \tau}+q^{*}$. This cap stands in contrast to most models of deposit insurance, which assume that the underlying assets have unlimited upside potential. 


\section{Deposit Guarantees under Interest Rate Uncertainty}

Most studies of government guarantees have been developed in a framework where there is only one source of uncertainty. When multiple sources of uncertainty are considered, many of these results are overturned. ${ }^{5}$

We now consider a model of deposit guarantees in which there are multiple sources of uncertainty. In particular, we consider the additional effect on guarantees when interest rates are stochastic. Clearly, interest rate risk interacts with asset risk, altering the overall risk exposure and affecting the value of the government subsidy. In this section, we explore how these two uncertainties affect the value of deposit guarantees.

Equation (14) gives the value of deposit insurance at date $\tau, G(\tau)$, under interest rate uncertainty. Substituting for $D(\tau)$ and $V(\tau)$ using equations (8), (10a), and (12a) yields

$$
G(\tau)=\max \left[0, K\left(\alpha, q ; q^{*}\right)+p^{E}\left(\tau, T ; q^{*}\right)\right]
$$

where

$$
K\left(\alpha ; q ; q^{*}\right)=\frac{D(0)}{P(0, \tau)}-\frac{1-q}{P(0, s)} P(\tau, s)-q^{*} P(\tau, T)
$$

and $p^{E}\left(\tau, T ; q^{*}\right)$ is given in equation (9a). The fair price of the deposit guarantee for this bank is given by

$$
G(0)=E_{0}\left[e^{-\int_{o}^{\tau} r(x) d x} G(\tau)\right]
$$

where the expectation is taken over the joint risk-neutralized process given by

\footnotetext{
${ }^{5}$ As an example, in an interest-rate-certain economy, capital regulations (as embodied in the current riskbased standards) and charter regulations are substitute policies. However, when interest rates are uncertain, Li et al. [1995] have shown that this result does not hold.
} 


$$
\begin{aligned}
& d r(t)=\mu_{r}(t) d t+\sigma d w(t) \\
& \frac{d A(t)}{A(t)}=\mu_{A}(t) d t+\sigma_{A} d z(t),
\end{aligned}
$$

with $A(0)=e_{f}+q$, and

$$
\begin{aligned}
& \mu_{r}(t)=\kappa[f(0, t)-r(t)]+\frac{\sigma^{2}}{2 \kappa}\left[1-e^{-2 \kappa t}\right]+\frac{d f(0, t)}{d t} \\
& \mu_{A}(t)=r .
\end{aligned}
$$

A bivariate binomial lattice was established to numerically determine the value for $G(0){ }^{6}$ Figure 5 shows the value of the government subsidy for loans with different maturities. Given any correlation coefficient, the graph indicates that the value of the government guarantee increases with maturity. It can also be seen that deposit guarantee values are more sensitive to maturity extensions when the correlation between interest rates and assets moves toward $-1 .^{7}$

Figure 6 shows the sensitivity of deposit guarantees to correlation changes for a fixed-maturity loan. As the correlation moves toward +1 , the riskless bonds and loan portfolio tend to form a natural hedge, reducing variability and decreasing the value of the government subsidy. If regulators are interested in the escalating costs associated with the moral hazard issues of deposit guarantees, then their policies should consider the nature of the loans made by banks and, in particular, the correlation effects between interest rates and the businesses in which the bank's customers operate.

\section{Conclusion}

We provide a model for deposit insurance that considers the bank's financing and investment decisions. In particular, we assume that the bank invests in a portfolio of default-free bonds and risky loans. Since the value of the risky loans depends on the investment decisions of the borrowing firm, the value of the deposit guarantee is connected to firm characteristics. By pushing back uncertainty to the level of the borrowing firm, we are able to explore how factors like firm leverage, loan maturity, and

${ }^{6}$ For a discussion of bivariate binomial lattice procedures, see Boyle, Evnine, and Gibbs [1989].

${ }^{7}$ Negative correlation implies that bond prices and loan portfolios are positively correlated. 
correlation effects between the assets of the firm and interest rates affect the value of the deposit guarantee. Future work will look at both the implications of alternative regulatory systems for deposit insurance and credit availability for bank customers.

Our model has some interesting implications for deposit insurance. First, we show that the correlation between different risks should be incorporated into any regulatory mechanisms for deposit guarantees, whether they are explicit (risk-based premiums) or implicit (regulatory taxes). Indeed, when banks face multiple sources of risk, regulators need multiple regulatory tools to minimize innovative risk-shifting behavior by insured banks. Second, we show that a consequence of deposit insurance is a preference by banks to increase the mismatch between the durations of their assets and liabilities, a phenomenon referred to by McCulloch [1981b] as misintermediation. ${ }^{8}$ Our numerical results are consistent with the increased average maturity of bank loans and earning assets shown in figures 2 and 3.

The fact that bank investments have limited upside potential implies that gains to shareholders from increased risk-taking are essentially capped. This implies that moral hazard considerations may be less important than previous analyses suggest.

In our analysis, we assume the existence of a representative firm. In practice, banks hold a portfolio of loans. While the direction of our results will remain unchanged, it is important to note that the beneficial role of reducing credit-related risk by diversifying loans is not captured. It remains for future work to establish models that assesss the impact of these additional portfolio effects.

\footnotetext{
${ }^{8}$ This maturity mismatch problem will be accentuated by the current risk-based capital guidelines, which asymmetrically tax credit and interest rate risks.
} 


\section{References}

Boyd, J., and M. Gertler, 1994, "Are Banks Dead, or Are the Reports Greatly Exaggerated?" Proceedings from a Conference on Bank Structure and Competition, Federal Reserve Bank of Chicago (May), 85-117.

Boyle, P., J. Evnine, and S. Gibbs, 1989, "Numerical Evaluation of Multivariate Claims," Review of Financial Studies 2, 241-250.

Buser, S. A., A. H. Chen, and E. J. Kane, 1981, "Federal Deposit Insurance, Regulatory Policy, and Optimal Bank Capital," Journal of Finance 36, 51-60.

Crouhy, M., and D. Galai, 1991, "A Contingent Claim Analysis of a Regulated Depository Institution," Journal of Banking and Finance 15 (January), 73-90.

Flannery, M. J., 1989, "Capital Regulation and Insured Banks' Choice of Individual Loan Default Risks," Journal of Monetary Economics 24, 235-258.

Flood, M., 1990, "On the Use of Option Pricing Models to Analyze Deposit Insurance," Federal Reserve Bank of St. Louis, Review 72 (January/February), 19-35.

Gorton, G., and R. Rosen, 1992, "Corporate Control, Portfolio Choice, and the Decline of Banking," Board of Governors of the Federal Reserve System, Finance and Economics Discussion Series No. 215 (December).

Heath, D., R. Jarrow, and A. Morton, 1992, "Bond Pricing and the Term Structure of Interest Rates: A New Methodology for Contingent Claims Valuation," Econometrica 60, 77-105.

Li, A., P. Ritchken, L. Sankarasubramanian, and J. B. Thomson, 1995, "Regulatory Taxes, Investment, and Financing Decisions for Insured Banks," Proceedings from a Conference on Bank Structure and Competition, Federal Reserve Bank of Chicago (May), forthcoming.

Marcus, A., 1984, "Deregulation and Bank Financial Policy," Journal of Banking and Finance 8 (December), 557-565.

McCulloch, J. H., 1981a, "Interest-Rate Risk and Capital Adequacy for Traditional Banks and Financial Intermediaries," in Sherman Maisel, ed., Risk and Capital Adequacy in Commercial Banks. University of Chicago Press and National Bureau of Economic Research, Chicago.

McCulloch, J. H., 1981b, "Misintermediation and Macroeconomic Fluctuations," Journal of Monetary Economics 8 (July), 103-115. 
Merton, R., 1977, "An Analytic Derivation of the Cost of Deposit Insurance and Loan Guarantees: An Application of Modern Option Pricing Theory," Journal of Banking and Finance 1 (June), 3-11.

Merton, R., 1978, "On the Cost of Deposit Insurance When There are Surveillance Costs," Journal of Business 5, 439-452.

Merton, R. C., and Z. Bodie, 1992, "On the Management of Financial Guarantees," Financial Management 21 (Winter), 87-109.

Penati, A., and A. Protopapadakis, 1988, "The Effect of Implicit Deposit Insurance on Banks' Portfolio Choices with an Application to International 'Overexposure'," Journal of Monetary Economics 21 (January), 107-126.

Ritchken, P., and L. Sankarasubramanian, 1991, "On Contingent Claim Valuation in a Stochastic Interest Rate Economy,' Case Western Reserve University, Technical Memorandum.

Ritchken, P., J. B. Thomson, R. P. DeGennaro, and A. Li, 1993, “On Flexibility, Capital Structure, and Investment Decisions for the Insured Bank," Journal of Banking and Finance 17, 1133-1146.

Toft, B., 1994, "Exact Formulas for Expected Hedging Error and Transaction Costs in Option Replication," University of California at Berkeley, Working Paper. 


\section{Appendix}

\section{Lemma (Toft [1994])}

Let $N(\bullet)$ and $N_{2}(\bullet, \bullet, \bullet)$ denote the univariate and bivariate standard normal distribution functions. Then,

$$
\int_{-\infty}^{\bar{x}} e^{-0.5\left(A x^{2}+B x+C\right)} N(D x+E) d x=\frac{\sqrt{2 \pi}}{\sqrt{A}} e^{-0.5\left(C-\frac{B^{2}}{4 A}\right)} N_{2}\left[\bar{x} \sqrt{A}+\frac{B}{2 \sqrt{A}}, \sqrt{\frac{A}{A+D^{2}}}\left(E-\frac{B D}{2 A}\right),-\frac{D}{\sqrt{A+D^{2}}}\right] \text {. }
$$

\section{Proof of Proposition}

At date $\tau$, the value of the government subsidy is given by

$$
G(\tau)=\max [0, D(\tau)-V(\tau)]
$$

We also have that

$$
\begin{aligned}
& B(\tau, T)=q^{*} e^{-r(T-\tau)}-p^{E}\left[\tau, T, q^{*}\right] \\
& I(\tau)=(1-q) e^{r \tau} \\
& V(\tau)=(1-q) e^{r \tau}+q^{*} e^{-r(T-\tau)}-p^{E}\left[\tau, T, q^{*}\right] \\
& D(\tau)=(1-\alpha) e^{r \tau}
\end{aligned}
$$

Substituting for $D(\tau)$ and $V(\tau)$, the time $\tau$ value of the government subsidy is given by

$$
G(\tau)=\max \left[0,(q-\alpha) e^{r \tau}-q^{*} e^{-r(T-\tau)}+p^{E}\left(\tau, T ; q^{*}\right)\right]
$$

If $V(\tau)<D(\tau)$, then the value of the government subsidy is

$$
G(\tau)=(q-\alpha) e^{r \tau}-q^{*} e^{-r(T-\tau)}+p^{E}\left(\tau, T ; q^{*}\right)
$$

Now,

$$
\operatorname{Pr}\{G(\tau)>0\}=\operatorname{Pr}\{D(\tau)>V(\tau)\}=\operatorname{Pr}\left\{p^{E}\left(\tau, T, q^{*}\right)>H(\tau, T)\right\},
$$

where

$$
H(\tau, T)=q^{*} e^{-r(T-\tau)}-(q-\alpha) e^{r \tau}
$$

The inequality for the put option will be satisfied when the underlying asset at date $t$, A(t), drops below some level $A^{*}$. Hence, the sought probability is equal to the probability of the event $\left\{A(\tau)<A^{*}(\tau)\right\}$, where the value $A^{*}(\tau)$ is obtained by solving the equation $p^{E}\left(\tau, T, q^{*}\right)=H(\tau, T)$, provided that $H(\tau, T)$ is positive. 
To solve this equation, we first need the value of $q^{*}$, which is a solution to

$$
q-q^{*} e^{-r T}+q^{*} e^{-r T} N\left(-d_{2}^{*}\right)-A(0) N\left(-d_{1}^{*}\right)=0,
$$

where

$$
\begin{aligned}
& d_{2}^{*}=\frac{\ln A(0) / q^{*}+\left(r-\sigma_{A}^{2} / 2\right) T}{\sigma_{A} \sqrt{T}} \\
& d_{1}^{*}=d_{2}^{*}+\sigma_{A} \sqrt{T}
\end{aligned}
$$

Then, $A^{*}$ is a solution to

$$
q^{*} e^{-r(T-\tau)}\left[N\left(-d_{2}\right)-1\right]-A^{*}(\tau) N\left(-d_{1}\right)-e^{r \tau}(\alpha-q)=0,
$$

where

$$
\begin{aligned}
& z^{*}=\frac{\ln A^{*}(\tau) / A(0)-\mu_{A} \tau}{\sigma_{A} \sqrt{\tau}} \\
& d_{2}=\frac{\ln A^{*}(\tau) / q^{*}+\left(r-\sigma_{A}^{2} / 2\right)(T-\tau)}{\sigma_{A} \sqrt{T-\tau}} \\
& d_{1}=d_{2}+\sigma_{A} \sqrt{T-\tau}
\end{aligned}
$$

Hence, $\operatorname{Pr}\{G(\tau)>0\}=\operatorname{Pr}\left\{A(\tau)<A^{*}(\tau)\right\}=\operatorname{Pr}\left\{z<z^{*}\right\}$.

In summary, then,

$$
\operatorname{Pr}\{G(\tau)>0\}= \begin{cases}1 & \text { if } H(\tau, T) \leq 0 \\ 0 & \text { if } H(\tau, T)>A(\tau) \\ \operatorname{Pr}\left\{A(\tau)<A^{*}(\tau)\right\} & \text { otherwise }\end{cases}
$$

The value of the government subsidy at date 0 is

$$
G(0)=e^{-r \tau} \tilde{E}_{0}[G(\tau)]
$$

where the expectation is taken under the risk-neutralized process. After substituting for $\mathrm{G}(\tau)$, we obtain: 
clevelandfed.org/research/workpaper/1995/wp9502.pdf

$$
\begin{aligned}
G(0)= & e^{-r \tau}\left[(q-\alpha) e^{r \tau}-q^{*} e^{-r(T-\tau)]}\right] N\left(z^{*}\right)+e^{-r \tau} \int_{A(\tau)<A^{*}(\tau)} q^{*} e^{-r(T-\tau)} N\left(-d_{2}\right) f(s) d s- \\
& e^{-r \tau} \int A(\tau) N\left(-d_{1}\right) f(s) d s \\
& A(\tau)<A^{*}(\tau)
\end{aligned}
$$

Now, using the Lemma to solve the three integrals and simplifying the resulting expressions leads to the final result. 


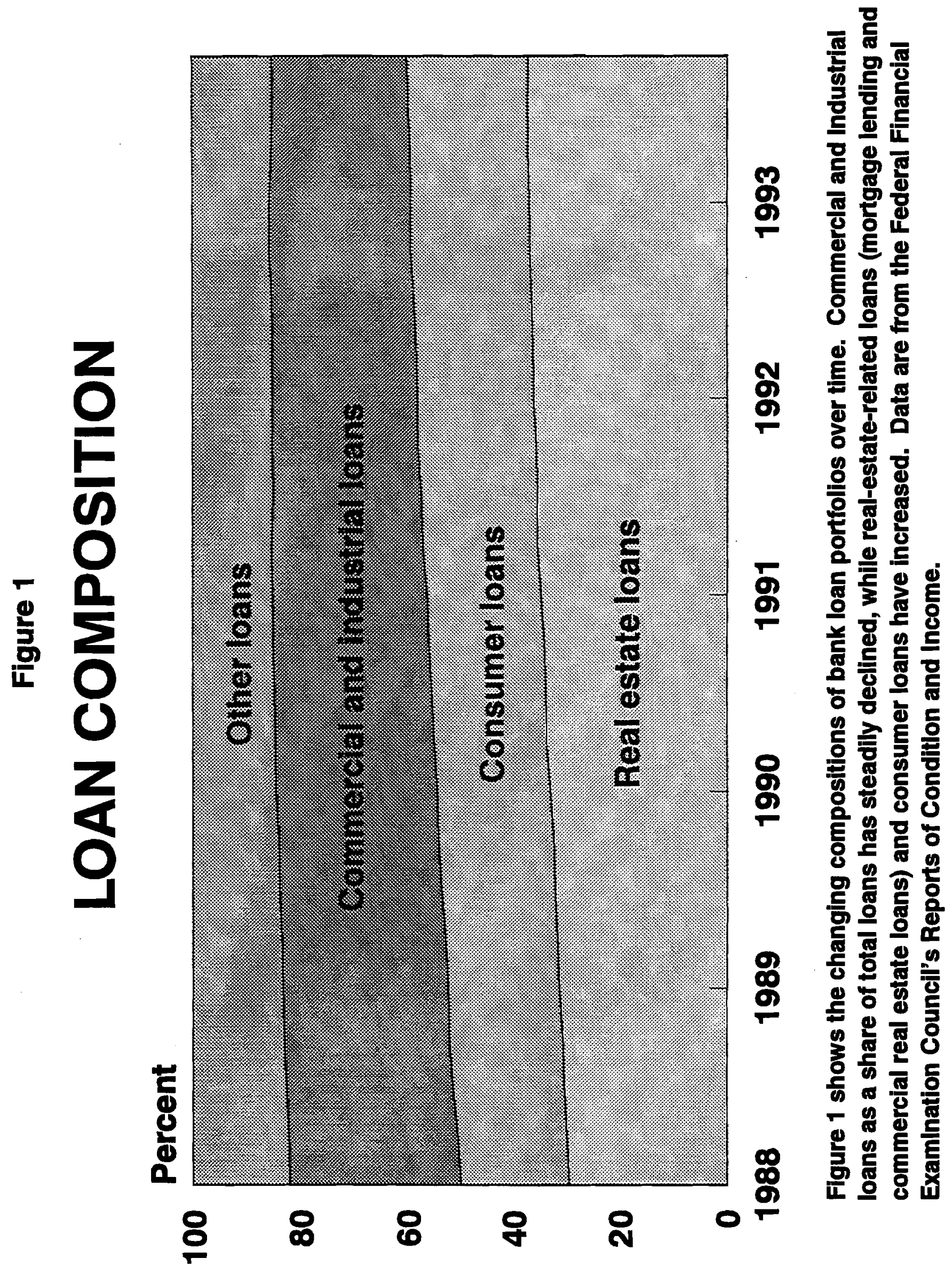


Figure 2

\section{EFFECTIVE ASSET MATURITY}

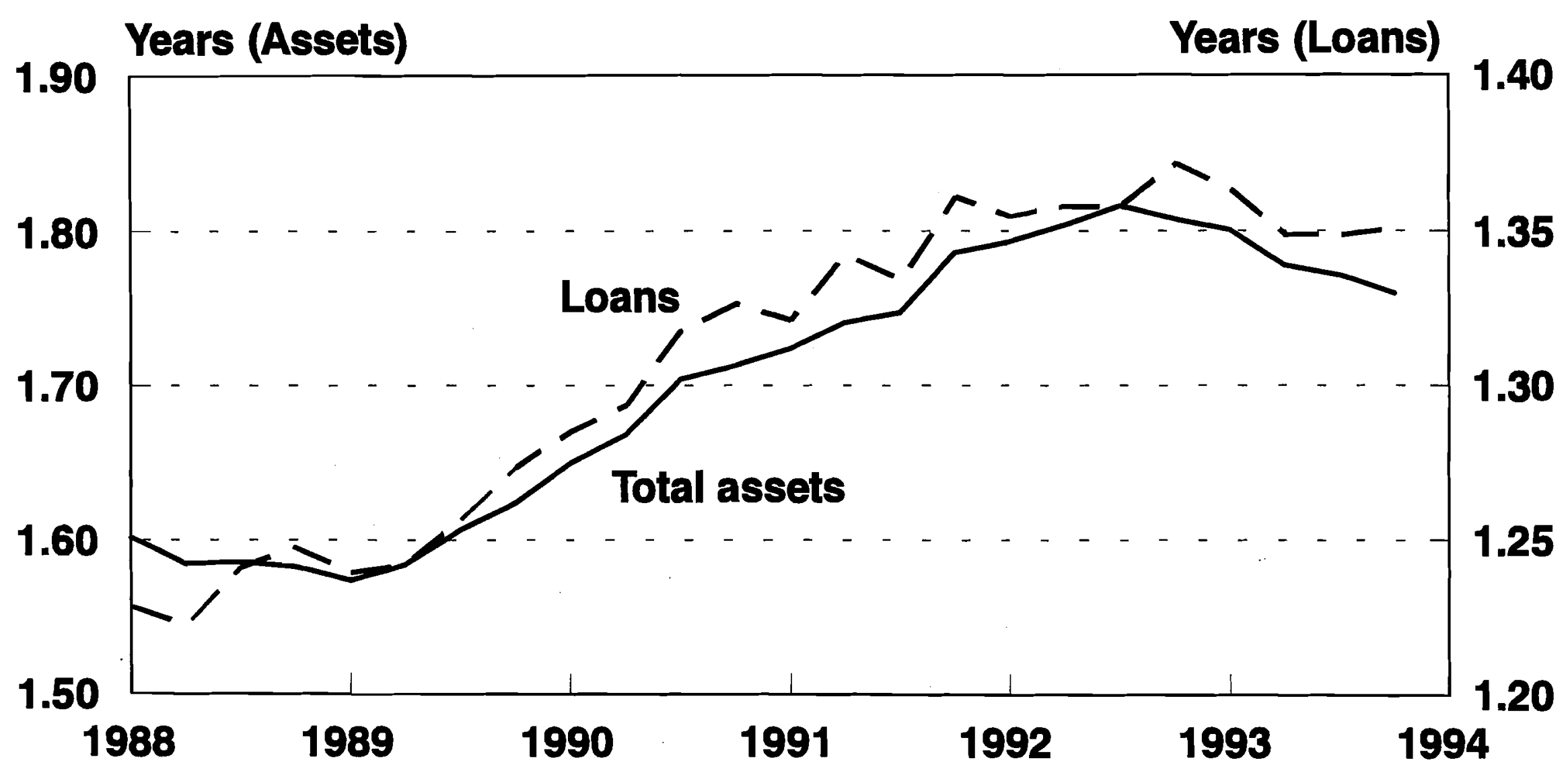

Figure 2 shows the lengthening effective maturity of bank loans and total bank assets. The sllght downturn In total asset maturlty after 1992 corresponds to a shortening of the maturlty of bank securlty portfolios in reaction to changes in accounting rules that forced banks to hold a higher percentage of their security portfollos at the lesser of book or market value. Effectlve maturity is computed using the maturity/repricing breakdowns reported on the Federal Financlal Examlnation Councll's Reports of Condition and Income. For both serles, the total doliar amount of assets In each maturity/repricing bucket is welghted by the midpoint of the maturity range (except for the greater-than-five-year bucket, which is given a weight of 5). 
Figure 3

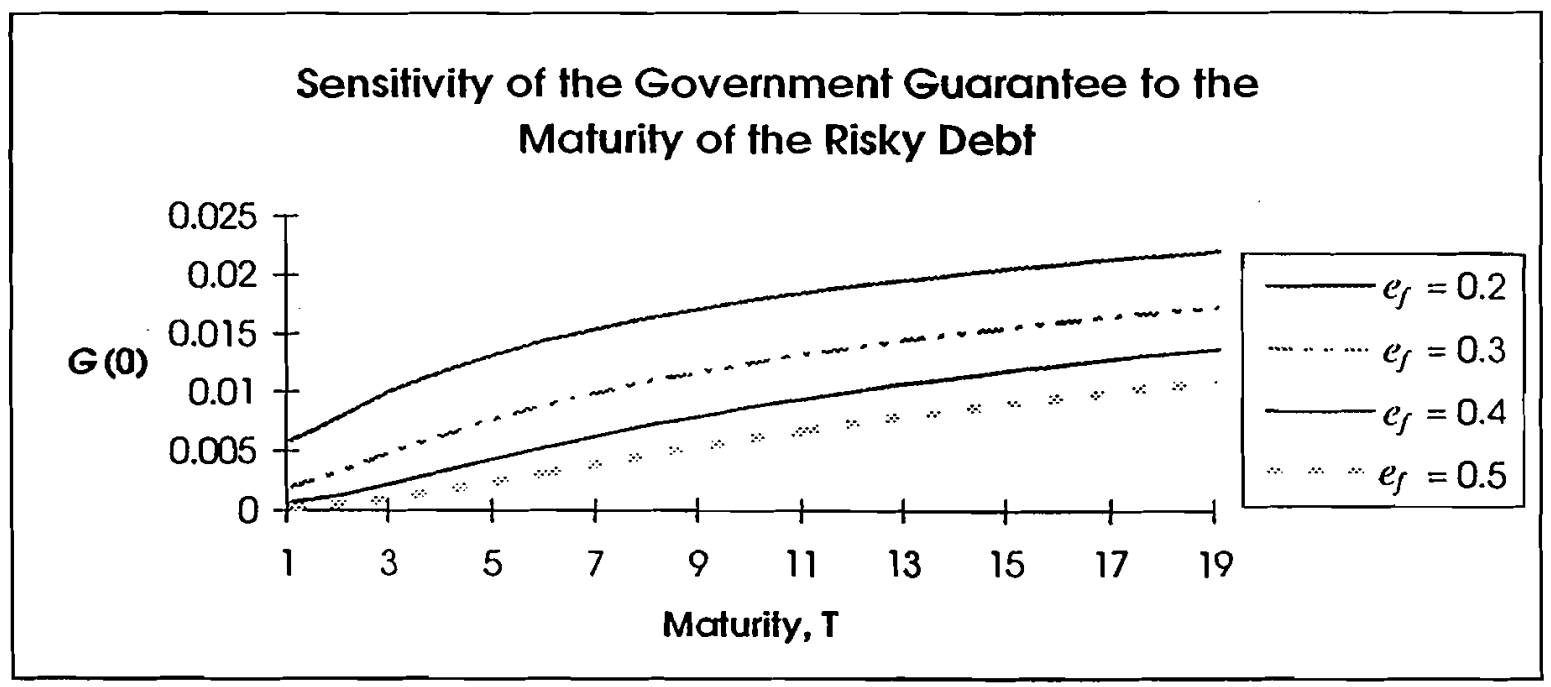

Figure 3 shows the sensitivity of the value of the government guarantee, $G(0)$, to extensions in the maturity of the risky loan. Each curve corresponds to a firm with a given leverage. As the leverage increases, shareholder equity, $e_{f}$ decreases, the risk expands, and the government guarantee becomes more valuable.

Source: Authors. 
Bank Shareholder Value as a Function of the Value of the Representative Firm

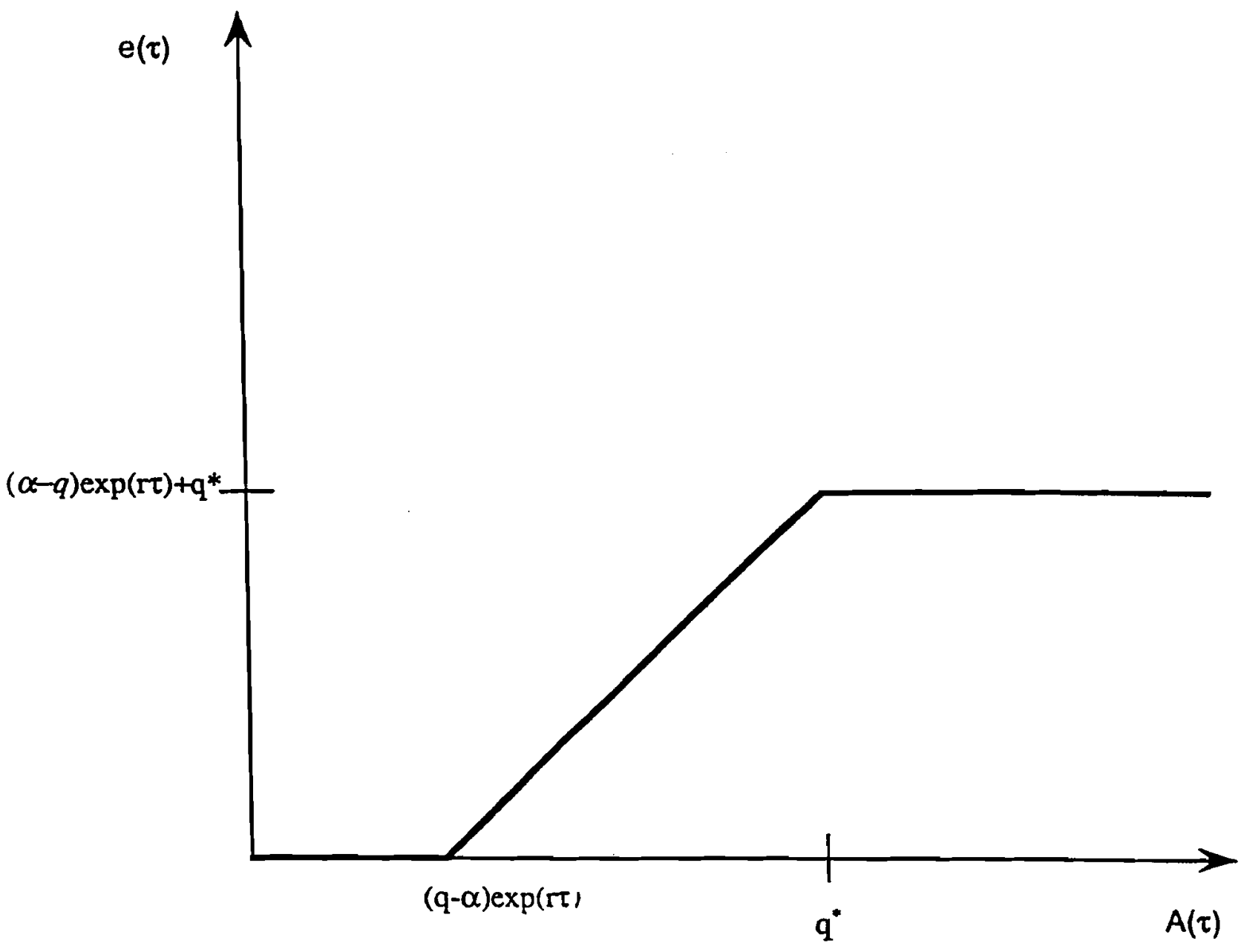

Figure 4 shows the terminal payoff to shareholders for the case $q>\alpha$. In this case, shareholder equity is zero if the value of the asset $A(\tau)$ falls below $(q-\alpha) \exp (r \tau)$. The maximum value for shareholders occurs when the face value of the loan is paid out. For all values of the firm larger than $q^{*}$, the shareholder value is capped.

Source: Authors. 


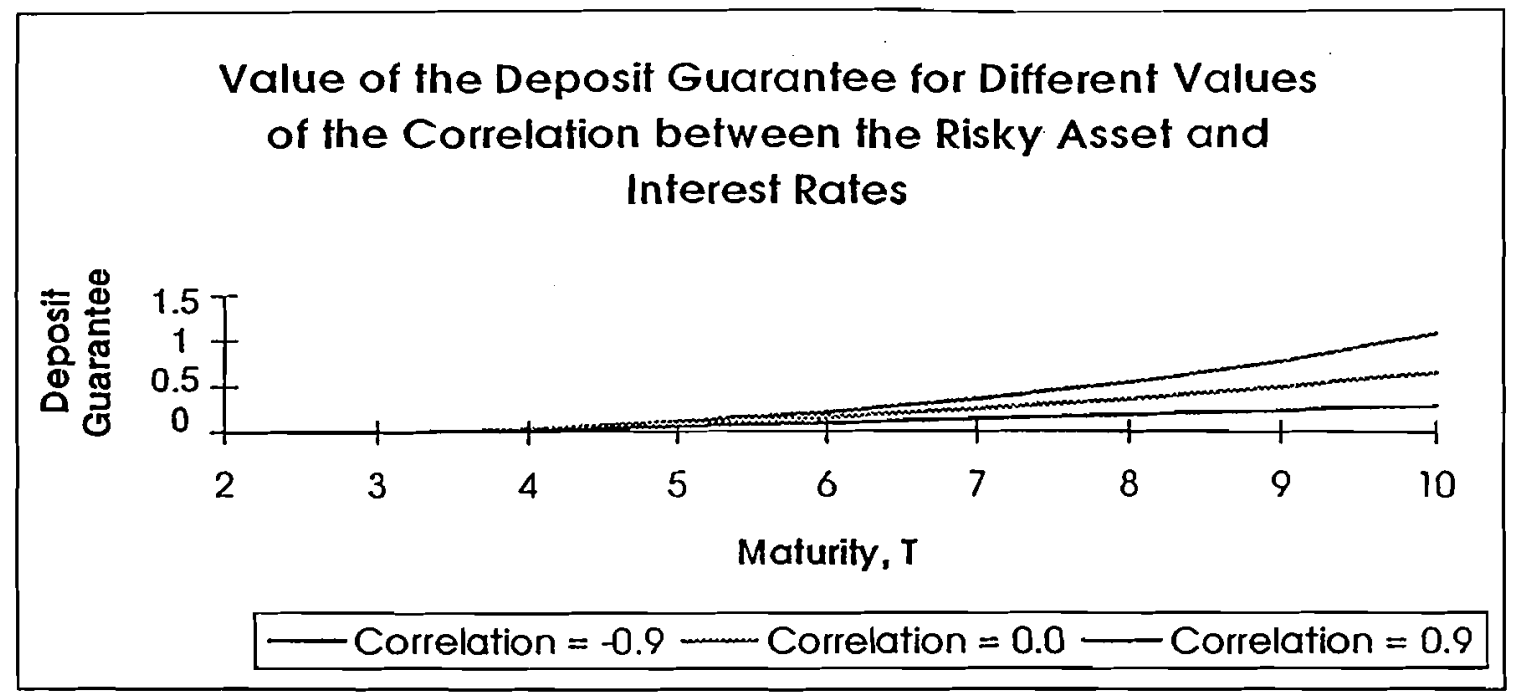

Figure 5 plots the value of the government guarantee against loan duration for different correlation coefficients between interest rates and the representative firm's assets. As the correlation increases, the default-free bond portfolio and the loan become natural hedges, decreasing the total price variability and hence the value of the deposit guarantee. For any correlation, the value of the guarantee increases with the duration of the loan. However, the rate of increase is enhanced when the firm's assets are most highly correlated with bond returns. The case parameters are as follows: The leverage of the representative firm was computed from $e_{f}=0.10$. The default-free investments were in $s=$ two-year bonds, with $q=0.8$. The volatility structure of forward rates was given by equation (5), with $\sigma=0.02$ and $\kappa=0.02$. The volatility of the assets was $\sigma_{A}=0.20$.

Source: Authors. 


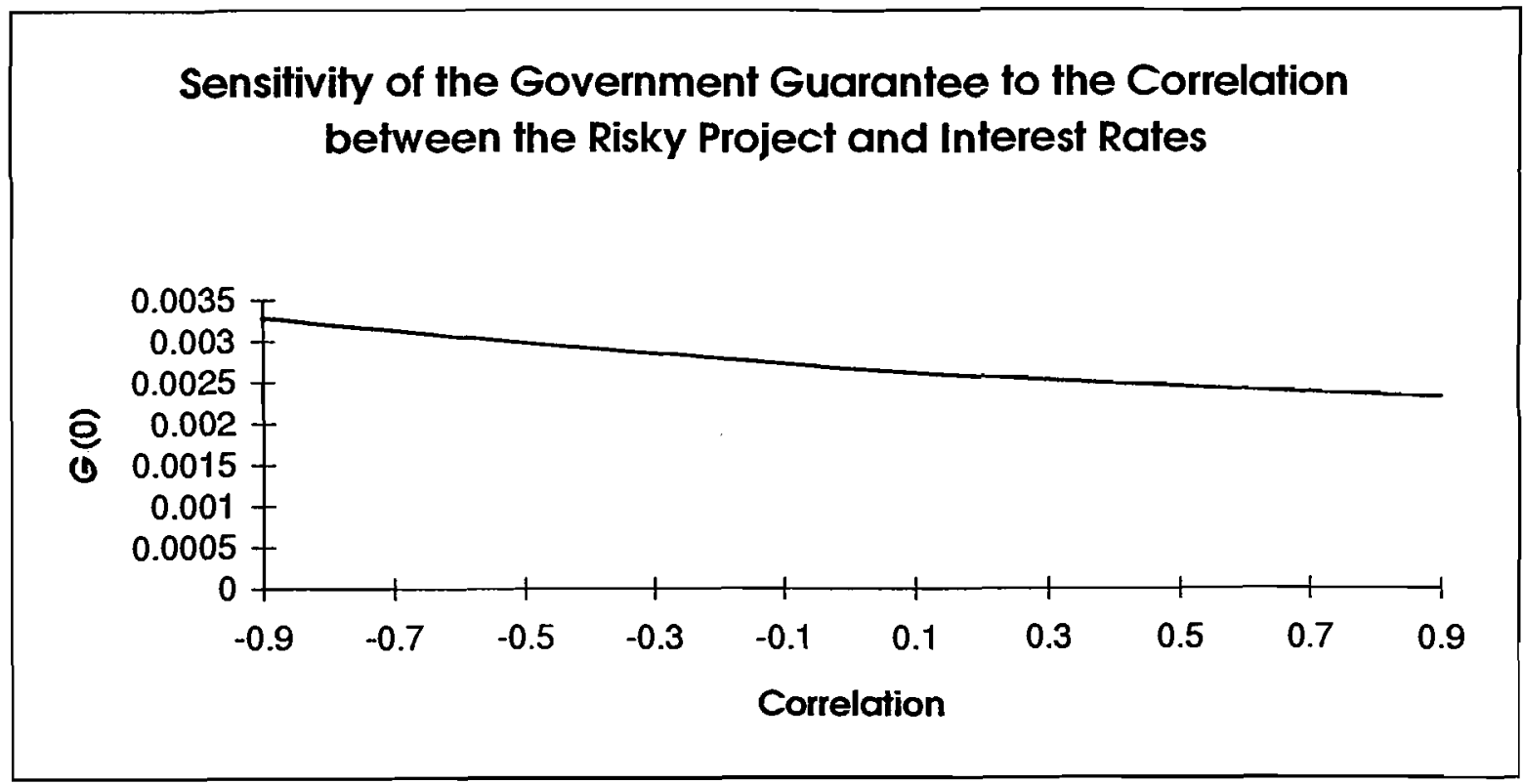

Figure 6 shows the effect of increasing the correlation between interest rates and the risky asset. The case parameters are as follows: The leverage of the representative firm was computed from $e_{f}=0.10$. The default-free investments were in $s=$ two-year bonds, with $q=0.8$. The volatility structure of forward rates was given by equation (5), with $\sigma=0.02$ and $\kappa=0.02$. The volatility of the assets was $\sigma_{A}=0.20$.

Source: Authors. 